
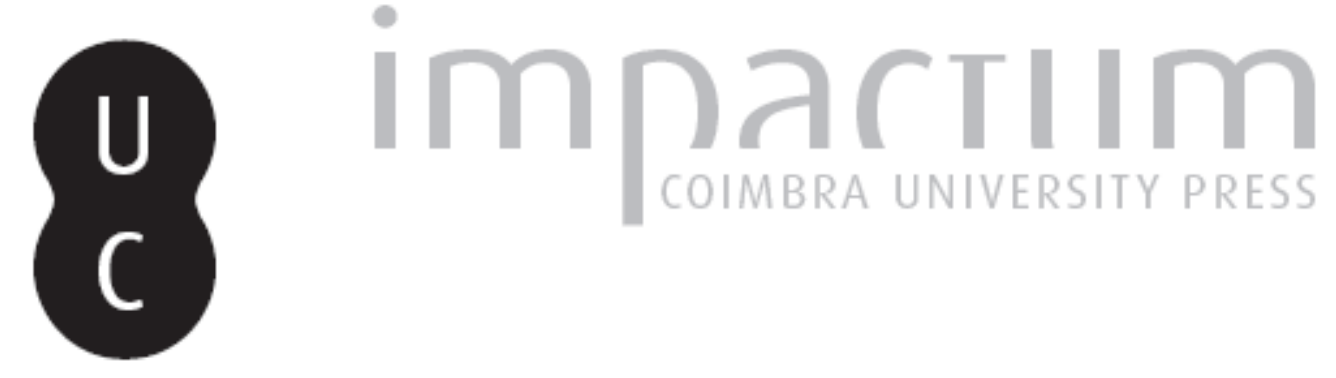

\title{
[Recensão a] G. Fabre; M. Mayer; I. Roda, Inscriptions Romaines de Catalogne: I. Barcelone (sauf Barcino)
}

Autor(es): D’Encarnação, José

Publicado por: Imprensa da Universidade de Coimbra

URL persistente:

URI:http://hdl.handle.net/10316.2/45590

DOI:

DOI:https://dx.doi.org/10.14195/1647-8657_27_7

Accessed : $\quad$ 26-Apr-2023 13:20:43

A navegação consulta e descarregamento dos títulos inseridos nas Bibliotecas Digitais UC Digitalis, UC Pombalina e UC Impactum, pressupõem a aceitação plena e sem reservas dos Termos e Condições de Uso destas Bibliotecas Digitais, disponíveis em https://digitalis.uc.pt/pt-pt/termos.

Conforme exposto nos referidos Termos e Condições de Uso, o descarregamento de títulos de acesso restrito requer uma licença válida de autorização devendo o utilizador aceder ao(s) documento(s) a partir de um endereço de IP da instituição detentora da supramencionada licença.

Ao utilizador é apenas permitido o descarregamento para uso pessoal, pelo que o emprego do(s) título(s) descarregado(s) para outro fim, designadamente comercial, carece de autorização do respetivo autor ou editor da obra.

Na medida em que todas as obras da UC Digitalis se encontram protegidas pelo Código do Direito de Autor e Direitos Conexos e demais legislação aplicável, toda a cópia, parcial ou total, deste documento, nos casos em que é legalmente admitida, deverá conter ou fazer-se acompanhar por este aviso.

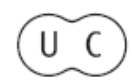


FACULDADE DE LETRAS

INSTITUTO DE ARQUEOLOGIA

\title{
CONIMBRIGA
}

\author{
VOLUME XXVII
}

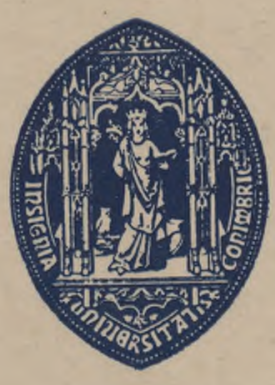

UNIVERSIDADE DE COIMBRA

1988 
G. FABRE; M. MAYER; I. RODA, Inscriptions Romaines de Catalogne: I. Barcelone (sauf Barcino), Diffusion De Boccard, Paris, 1984, 250 pages -f- pl. LXVIII; IL Lérida, ibidem, 1985, 176 pages + pl. LVIL Publications du Centre Pierre Paris, volumes 13 et 15 (= volumes 22 et 28 de la Collection de la Maison des Pays Ibériques).

A grande utilidade destes dois corpora é, sem dúvida, a de terem reunido todos os monumentos epigráficos conhecidos de Barcelona e de Lérida.

Os autores rejeitaram os textos cuja tipologia, cujo foimulário, cujo material (de realçar a importante pesquisa levada a efeito acerca do suporte numa perspectiva geológica) ou outros motivos Ibes apontaram uma proveniência alheia e aceitaram, da mesma forma, os textos considerados de outras zonas e dos quais uma cuidadosa análise viria a sugerir uma origem mais precisa e mais verosímil.

Não estava inédita a quase totalidade dos 307 textos aqui estudados. Inclusive sobre Lérida, fizera F. Lara Peinado, em 1973, a obra Epigrafia Romana de Lérida. Mas os autores justificam que, mesmo assim, o seu trabalho não será inútil, se se tiver em consideração que esse corpus não apresenta qualquer rigor metodológico, tem erros de interpretação e não aborda criticamente a questão dos monumentos falsos, que toma por autênticos (II, p. 11). Na verdade, foi sistemática a pesquisa efectuada nesse sentido, num sempre louvável e nunca por de mais sublinhado regresso ao monumento. A exclusão do perímetro urbano de Barcelona tem, igualmente, uma justificação: a existência da obra do saudoso Sebastián Mariner Bigorra, Inscripciones Romanas de Barcelona (Lapidarias y musivas) (Parte primera — texto, Barcelona, 1973).

Com efeito, estes dois volumes são, antes de mais, catálogos epigráficos. Como se assinala nas respectivas introduções, é o estudo do monumento que particularmente interessa aos autores, tanto do ponto de vista externo (matéria-prima do suporte, tipologia das epígrafes, molduração) como interno (paleografia, formulários, conteúdo do texto).

A introdução é, de facto, em cada um dos volumes, já uma panorâmica das conclusões a que os autores chegaram. Preferir-se-ia, quiçá, que essas conclusões viessem no final ou, inclusive, que fossem reservadas para um eventual volume de síntese. E, aponto, a corroborar essa preferência, dois aspectos.

$\mathrm{O}$ primeiro diz respeito às moldurações. Ilouve o cuidado de incluir o desenho da quase totalidade das molduras representadas; no entanto, a circunstância de terem sido incluídas em páginas diferentes e numa escala muito pequena, aliada ao facto de o texto a esse respeito ser diminuto e pouco esclarecedor, não dá azo às conclusões que certamente se tirarão se à molduração for dedicada uma atenção maior, um capítulo, porque (não há dúvida) após os trabalhos de Jean-Noël Bonneville esse é um domínio com interesse a explorar. Mas não na genérica introdução a um catálogo. 
O segundo ponto refere-se à relação entre a escolha de um tipo de monumento epigráfico por parte de uma determinada população ou estrato populacional. Trata-se de uma questão de índole cultural que, à partida, não tem cabimento num catálogo exclusivamente epigráfico. Fica bem, isso sim, nas conclusões, designadamente se, na economia desse catálogo, elas tiverem lugar. Ora, os autores optaram por ser exclusivamente epigrafistas. Uma opção corajosa, perfeitamente defensável, se considerarmos que se encara a possibilidade de o volume $\mathrm{V}$ da série ter, além dos índices informatizados (I, p. 6), as sínteses decorrentes dos vários domínios estudados (é expressamente assinalado — vol. I, p. 14 - que conterá as conclusões de âmbito geológico, um dos aspectos inovadores desta pesquisa). Nesse caso, surgem, em meu entender, desgarradas de contexto as referências (aliás, importantes) a essa clientela de cada um dos tipos de monumentos feitas quase no final da introdução do vol. II (p. 24), ou a alusão ao facto de as inscrições religiosas presentes em zonas rurais constituírem «sobrevivências de cultos locais» (I, p. 10), que é outra das conclusões inovadoras a que se chegou. Ou seja, por outras palavas, os autores assumiram-se como epigrafistas mas não deixaram de apontar, aqui e além, mas de forma não sistemática, conclusões de âmbito histórico-cultural. Não veria, pois, com maus olhos, que essasconclusões tivessem sido, depois, sistematizadas num capítulo final. Ganhar -se-ia em clareza e eficácia e aí seriam tidos no seu real valor os oportunos mapas apresentados, que servem, de facto, uma síntese afinal, inexistente.

Um outro pormenor que me merece comentário diz respeito à arrumação dos textos no livro. Será, por exemplo, discutível a distribuição por comarcas, quando se verifica que elas não correspondem às divisões administrativas romanas, impossíveis já de definir actualmente (I, p. 7) e quando algumas delas não dispõem de um número significativo de monumentos. Estou a lembrar-me, por exemplo, de Alt Urged (I, p. 103-104) ou de Garrigues (II, p. 127-128), com um único monumento cada. Talvez tivesse sido menos fragmentário optar por uma apresentação temática, até porque, segundo creio, o objectivo não é elaborar a carta epigráfica de cada comarca mas dar uma panorâmica da epigrafia de cada província. Nesse mesma ordem de ideias, também não me pareceu suficientemente justificado o critério de arrumação dos textos por microtopónimos, dentro de cada comarca, atendendo a que houve o louvável cuidado de preparar mapas onde graficamente se observa a distribuição geográfica dos achados.

$\mathrm{O}$ estudo de cada monumento obedece ao esquema ensaiado, com êxito, no volume II das Fouilles de Conimbriga (Paris, 1976): indicação precisa dos locais de achamento e de conservação, descrição minuciosa, leitura, tradução, bibliografia, variantes de leitura, comentário paleogràfico e comentário de integração histórica.

As alturas das letras são mencionadas sem uma referência expressa às linhas a que se referem. Parte-se do princípio que se começa pela linha 1 e se vai por aí adiante; mas, se faltar uma medida, é a da última linha ou a da primeira? Exemplifico logo com a inscrição n. ${ }^{\circ} 1$ do vol. II: se é dada 
sem ponto de interrogação a medida do último espaço interlinear (39), é porque se consegue medir a altura das letras da linha 5, mas são só dadas quatro medidas. Yeja-se também o . $^{\circ} 75$ desse mesmo volume: há cinco linhas e só são mencionadas as medidas de quatro. O mesmo se diga dos espaços interlineares: no $\mathrm{n}^{\circ} 2$ do vol. II falta a medida de um espaço - qual é?

O texto é apresentado em maiúsculas, respeitando a divisão de linhas epigráficas, utilizando-se os habituais sinais diacríticos.

A bibliografia vem indicada uma primeira vez com todas as informações, assinalando-se aí como passará a ser citada depois; trata-se de um esquema referencial nem sempre cómodo (porque um catálogo epigráfico é um livro de consulta e não um romance que se lê do princípio ao fim) e que seria dispensável se tivermos em linha de conta que existe, no final de cada volume, uma bibliografia por ordem alfabética de autores.

$\mathrm{O}$ comentário paleogràfico começa pela observação dos caracteres e só depois se refere à paginação. A referência à pontuação, à existência de nexos, inclusões ou linhas de pauta é feita à parte, imediatamente após a indicação das variantes de leitura. Confesso a minha fidelidade ao esquema utilizado no volume II das Fouilles de Conimbriga. Penso que a referência à paginação não só deve preceder a análise gráfica dos caracteres como deve incluir também as anotações alusivas à pontuação, nexos, inclusões, linhas de pauta, porque tudo isso é, em meu entender, parte integrante da paginação, ou seja, são os meios de que o ordinator se serve para dispor o texto desta ou daquela maneira no campo epigráfico.

Yem, finalmente, o comentário de integração histórica. Num catálogo, é difícil saber até onde se deverá ir para que se não diga nem demais nem de menos. Uma regra é, porém, extraordinariamente preciosa: tudo o que se disser há-de ser rigoroso, na consciência plena das limitações a que a própria índole do trabalho nos obriga. Podemos apontar pistas, mas há que sublinhar, em cada caso, o seu valor, nomeadamente através da indicação precisa das fontes utilizadas e, sobretudo, do âmbito cronológico da nossa pesquisa (isto porque não é segredo para ninguém que, muitas vezes, uma obra pode sair com uma data um, dois, três ou mesmo quatro anos posterior àquela em que o manuscrito foi entregue na tipografia). Os autores souberam manter o desejável equilíbrio e demonstraram ter bem presente todo o acervo da documentação epigráfica peninsular, designadamente no âmbito da onomástica e da religião.

Há, no fim de cada volume, bons e muito úteis índices epigráficos: nomina, cognomina, imperadores, magistrados, exército, indicações geográficas, tribos, organização municipal, religião, collegia, textos métricos, listas de concordância com outros corpora; índice de locais de proveniência, índice dos actuais paradeiros dos monumentos.

Completam os volumes as páginas de fotografias. De um modo geral, são aceitáveis. A iluminação nem sempre foi cuidada (I, pi. XXV e LXIII), a possibilidade de isolar o monumento das outras peças que o ladeiam não foi habitualmente tentada in situ ou mesmo no laboratório (cf. vol. II, pl. XLVIIÏ 
e XLIX), inclusive retirando as etiquetas museogràfîcas (cf. vol. II, pi. XXV e XLVII). Penso que os próximos volumes requererão, nesse particular, mais atenção.

Mas convenhamos que não é fácil para o epigrafista resistir à tentação de ser historiador. Georges Pabre, Marcos Mayer e Isabel Rodà escolheram o bom caminho: primeiro, o estudo preciso, completo, dos monumentos, de todos os monumentos; a síntese histórica virá depois, sólida, bem fecundada por todos os ensinamentos da Epigrafia. Ficamos, pois, a aguardar os outros volumes anunciados - o III sobre Gerona, o IV sobre Tarragona (excepto Tarraco) e, sobretudo, o V de índices e de síntese final.

JOSÉ D'E NCARNAÇÂO

\section{Antonio rodríguez Colmenero, Aquae Flaviae: I-Fontes Epigráficas,}

Chaves, Cámara Municipal de Chaves, 1987, 755 p.

Com uma «Nota prévia» de João Baptista Martins e um «Prólogo» de Jürgen Untermann, foi editada uma obra importante para o estudo da romanização do Norte de Portugal e da Galiza. Trata-se de um vasto corpus que reúne quase todas as inscrições duma grande região, cuja principal cidade na Antiguidade era Aquae Flaviae.

Bem andou a Câmara Municipal de Chaves quando patrocinou o estudo de uma parte valiosíssima do seu património cultural. Quem realizou tal tarefa foi António Rodríguez Colmenero, que tivemos o prazer de conhecer no Museu da Região Flaviense, precisamente quando ali realizámos uma rápida análise da epigrafia votiva guardada naquela instituição. Nessa ocasião, preparava Colmenero o volume que ora merece a nossa atenção. Devido à sua amabilidade, que muito agradecemos, facultou-nos algum tempo depois uma primeira versão do seu trabalho, que utilizámos de forma crítica na obra acima referida. Aí tivemos ocasião de expressar algumas dúvidas sobre as perspectivas de leitura e interpretação do autor, que mais à frente iremos retomar.

Este primeiro volume de Aquae Flaviae encontra-se dividido em vários capítulos, cujos títulos passamos a transcrever: I. Inscrições votivas (p. 12-256); II. Inscrições funerárias (p. 257-387); III. Epígrafes viárias (p. 385-545); IV. Inscrições honorárias (p. 546-603); V. Epígrafes jurídicas (p. 604-651); VI. «Instrumentum domesticum» (p. 652-681); Conclusões (p. 682-685); últimas inscrições aparecidas (p. 686-691), a que se seguem tábuas de abreviaturas, bibliografia, tábuas de correspondências e índices.

Colmenero reuniu neste volume 533 peças, mas há a considerar que algumas delas foram inadvertidamente repetidas e outras não têm inscrições 